\title{
HISTORIA Y HERMENÉUTICA
}





\author{
Chinatsu Kobayashi ${ }^{\mathrm{I}}$ \\ Université du Québec à Montréal, Canadá \\ c.kobayashi.marion@gmail.com

\section{Mathieu Marion} \\ Université du Québec à Montréal, Canadá \\ marion.mathieu@uqam.ca
}

\title{
Gadamer y Collingwood sobre la distancia temporal y la comprensión ${ }^{2}$
}

\author{
Gadamer and Collingwood on Temporal Distance and \\ Understanding
}

\section{Gadamer e Collingwood sobre a distância temporária e da compreensão}

Artículo de reflexión recibido el oI/I2/II y aprobado el o7/O5/I2

I Nota del editor: CS agradece a Copyright Clearance Center's RightsLink Service y a la editorial John Wiley and Sons por concedernos el permiso para publicar este artículo en nuestra revista. Igualmente, damos las gracias a Chinatsu Kobayashi y Mathieu Marion por aceptar publicar su trabajo con nosotros. Este artículo apareció en History and Theory, diciembre de 20II, bajo el título "Gadamer and Collingwood on Temporal Distance and Understanding”. La traducción del inglés al espańol es de Asher Gutkind. Revisión final de Rafael Silva Vega.

2 Los argumentos de este trabajo se originaron en un seminario de investigación dictado por Mathieu Marion y Benoît Castelnérac en Université de Sherbrooke, y en una presentación por Chinatsu Kobayashi para un seminario en Historia del Arte en la Université du Québec à Montréal, ambos en 20Io. Una primera versión de este artículo sirvió de base, en julio de 20Io, a una conferencia en el R. G. Collingwood Society Conference en el Palazzo Datini, Prato. Agradecemos a James Connelly, Giuseppina D’Oro, Karsten Stueber y, especialmente, a Jan van der Dussen por las provechosas conversaciones y comentarios sobre la primera versión de este trabajo, así como a Rik Peters por sus observaciones, su paciencia y por la sugerencia de que publicaramos este este artículo luego de una revisión.. 



\title{
Resumen
}

En este trabajo, sugerimos un modelo intuitivo del tiempo, trabajado en la hermenéutica de Gadamer, pero que es rechazado por Collingwood. Para mostrarlo, examinamos la respuesta de cada uno al problema de la transposición, sobre el que la filosofía de Dilthey se ha fundado supuestamente. Discutimos luego sobre las nociones implícitas de tiempo, mostrando que Ricoeur tiene una mejor apreciación del asunto, por lo que ve que Collingwood se mueve paralelamente, hasta cierto punto, a la crítica de Heidegger del "tiempo vulgar", aunque con un resultado enteramente diferente. Apuntamos también la importancia en el pensamiento de Collingwood, de su noción de "encapsulación” (“incapsulation”).

Palabras clave: Tiempo, Distancia, Comprensión, Intención, Gadamer, Collingwood, Dilthey, Ricoeur.

\begin{abstract}
In this article, the authors explore an intuitive model of time worked through in Gadamer's hermeneutics, but which is rejected by Collingwood. To illustrate this, the authors examine the responses of both to the problem of transposition, upon which Dilthey's philosophy is purportedly founded. The authors then discuss the underlying notions of time, demonstrating that Ricoeur had a greater appreciation of the issue, given his observation that Collingwood moves parallel to Heidegger's critique of "vulgar time" to a certain extent, albeit with an entirely different result. In addition, the authors highlight the importance of Collingwood's thinking to his notion of "incapsulation".
\end{abstract}

Keywords: Time, Distance, Understanding, Intention, Gadamer, Collingwood, Dilthey, Ricoeur

\section{Resumo}

Nesse trabalho, sugerimos um modelo intuitivo do tempo, trabalhado na hermenêutica de Gadamer, mas rejeitado por Collingwood. Para mostrá-lo, examinamos a resposta de cada um ao problema da transposição, sobre o que supostamente a filosofia de Dilthey foi fundada. Discutimos depois sobre as noçóes implícitas de tempo, mostrando que Ricœur tem uma melhor apreciação do assunto, pelo que vê que Collingwood se move paralelamente, até certo ponto, para a crítica de Heidegger do "tempo vulgar", ainda que com um resultado inteiramente diferente. Mostramos também a importância no pensamento de Collingwood, de sua noção de "encapsulação" ("incapsulation").

Palavras-chave: Tempo, Distância, Compreensão, Intenção, Gadamer, Collingwood, Dilthey, Ricœur 



\section{La distancia temporal como problema}

Según un modelo intuitivo del tiempo, el presente es como una línea sin espesura que separa el pasado del futuro, una especie de puerta a través de la cual los eventos fluyen desde el futuro hacia el pasado. Una vez que un evento pasa a través de esa puerta deja de existir, de algún modo desciende progresivamente hacia el pasado, llevado por el flujo del tiempo y seguido por futuros eventos, mientras pasan a través del presente, en una manera ordenada. Desde luego, el pasado se convierte en "aquel gran contenedor" del que Arthur Danto habló al principio del capítulo viII de Analytical Philosophy of History, quien demolió, a su manera, un modelo bastante similar (Danto, 2007). Él no fue el primero en hacerlo, R. G. Collingwood ya lo había criticado, aunque con distintos fundamentos, en sus "Lectures on the Philosophy of History" (1926). En efecto, hay muchas dificultades con este modelo que no trataremos aquí. Quisiéramos poner el énfasis sobre la presencia implícita de metáforas espaciales: de hecho, la misma idea de un evento pasado que está más alejado de nosotros que otro ya es una metáfora espacial. Aquel "hábito de 'espacializar' el tiempo", como lo formuló Collingwood (1994), genera lo que quisiéramos llamar "el problema de la distancia temporal": cada año que pasa nos aleja más de los eventos pasados; la inquietud consiste en: entre más se alejan los eventos hacia el pasado, menos accesibles se vuelven para nosotros. Esa suerte de inquietud se agrava con la idea de que cuanto más, un evento pasado, se aleja de nosotros en el tiempo tanto más probable es que las huellas que ha dejado tras de sí, si las hay, vayan a desaparecer, también, haciéndonos cada vez más difícil entender lo que ha pasado. Uno debería notar la manera en que esta idea provee un apoyo implícito para al escepticismo, ya que las dificultades prácticas se convierten subrepticiamente en cuestión de principio. Ni siquiera se necesita adoptar, por ejemplo, una tesis constructivista fuerte según la cual el evento simplemente no existe, o no está determinado completamente, por lo que cualquier narrativa sobre él es una pura construcción de nuestra parte. Sólo hace falta que uno cruce la línea entre una dificultad práctica muy real que uno enfrenta al reconstruir una secuencia de eventos y la imposibilidad de hacerlo, porque en muchos casos no hay suficientes pruebas para fundamentar con certeza una reconstrucción con respecto a otra. Al generalizar este pensamiento se genera escepticismo, de la misma manera en que al ver un bastón doblado en el agua se nos prueba que nuestros sentidos nos engañan; generalizar a partir de esto nos lleva al escepticismo acerca de la percepción sensible. Este camino se hizo conocer en la teoría del conocimiento, cuando fue criticada por J.L. Austin. ${ }^{3}$ Quentin Skinner ha criticado un movimien-

3 Para el argumento de la ilusión, de A. J. Ayer (1940), que es uno de los blancos de la crítica de Austin (I962). 
to ilícito similar en Espolones de Jacques Derrida, quien a partir de un fragmento solitario de Nietzsche, "Me olvidé de mi paraguas", para el cual ningún contexto puede reconstruirse, realiza la generalización apresurada que afirma que nunca podemos saber con seguridad lo que un autor quiso decir. ${ }^{4}$

Cuando viene el momento de comprender las culturas del pasado, el problema se vuelve más dramático: no solamente la cultura que uno estudia puede haber desaparecido desde hace mucho tiempo, sin que hayan quedado huellas sobre las cuales fundamentar nuestras inferencias, sino que, además, nos enfrentamos a los argumentos relativistas sobre la imposibilidad de comprender otras culturas diferentes de las nuestras, con la misma generalización implícita, desde una dificultas práctica, en algunos casos, a una imposibilidad de principio.

Supongamos ahora que uno desea entender el pensamiento de un miembro de aquellas culturas desaparecidas desde hace mucho tiempo, sobre la base de escritos que han sobrevivido hasta hoy: ¿habría alguna esperanza de restituir la intención del autor?5 Si usted ha estado de acuerdo con el escéptico, entonces la respuesta sería obviamente negativa. De hecho, una respuesta negativa a esta pregunta es uno de los prejuicios más enraizados de nuestra propia sofisticada cultura filosófica, así que cualquier argumento que busca apoyarlo tendrá crédito

4 Ver Q. Skinner (200I), pp. 179. El paso ilícito de Derrida proviene de la afirmación "We will never know for sure what Nietzsche wanted to say or do when he wrote these words" (Skinner, I979: I23), to the stronger claim that "We will never know. At least it is possible that we will never know and that powerlessness (impouvoir) must somehow be taken into account. Much as a trace which has been marked in what remains of this nonfragment, such an account would withdraw it from any assured horizon of a hermeneutic question" (Skinner, 1979: 127). Por supuesto, su discusión gira en torno a "I have forgotten my umbrella", pero las conclusiones de Derrida no están destinadas a limitarse a casos similares, Derrida obviamente deseó sacar de ello una conclusión general. De otra manera su discusión hubiese sido de muy poco interés. Debemos saber que la posición criticada no corresponde a la hermenéutica de Gadamer, sino a una versión tradicional de la hermenéutica como la de Schleiermacher o la de Dilthey, que Derrida debió retomar de sus lecturas de Heidegger. No tenemos conocimiento de ninguna razón, por ejemplo leyendo a D. P. Michelfelder \& R. E. Palmer (I989), para creer que Derrida conoció la filosofía de Gadamer antes de su muy famoso encuentro en Paris en I98I (mientras que el contrario no era cierto). A lo largo de Espolones, Derrida etiqueta a su oponente como "l'herméneute" (el hermeneuta), aunque hable por ejemplo de "the hermeneutic project which postulates a true sense of the text" (Skinner, 1979: 107). Esto, por supuesto, no es la tesis sostenida por Gadamer.

5 En este trabajo vamos a pasar sin previo aviso de la consideración de las acciones de los agentes históricos a la consideración de la interpretación de los textos pasados, para hacer frente al hecho de que Collingwood enfoca más bien el primero, mientras que Gadamer enfoca más bien este último, y también de acuerdo con una tesis subyacente sobre la universalidad de la teoría de la interpretación, que fue reconocida por Collingwood mismo: "Si es por el pensar histórico que re-pensamos y así redescubrimos el pensamiento de Hammurabi o de Solón, es por el mismo camino que descubrimos el pensamiento de un amigo que nos escribe una carta, o un desconocido que cruza la calle. Tampoco es necesario que el historiador deba ser una persona y el objeto de su investigación otra. Es sólo mediante el pensar histórico que puedo descubrir lo que yo pensaba hace diez ańos, leyendo lo que entonces escribí, o lo que yo pensaba hace cinco minutos, reflexionando sobre una acción que hice entonces, que me sorprendió cuando me di cuenta de lo que había hecho. En este sentido, todo conocimiento de la mente es histórico. La única manera en que puedo conocer mi propia mente es realizando algún acto mental y, luego, viendo lo que es ese acto realizado" (Collingwood, 1993: 219). 
no porque éste convenza que es la respuesta adecuada sino porque corresponde a lo que se quiere oír. El supuesto "linguistic turn"6 en la filosofía de la historia ha importado también una nueva capa discursiva proveniente principalmente de la filosofía francesa estructuralista y post-estructuralista y de la teoría literaria con el propósito de aportar un apoyo abrumador a una respuesta negativa. Son asuntos muy amplios que por supuesto no pretendemos tratar exhaustivamente aquí. Deseamos sencillamente presentarlos como telón de fondo de nuestra discusión. Si usted es lo suficientemente filósofo como para cuestionar los prejuicios, quiza usted está listo para cuestionar el modelo subyacente del tiempo por su incoherencia, y observar su efecto deletéreo sobre estos asuntos. Nuestra afirmación, en pocas palabras, será, desde luego, que el modelo intuitivo del tiempo queda sin ser cuestionado en la hermenéutica de Gadamer, mientras que la teoría de la interpretación y la filosofía de la historia de Collingwood se basan sobre su explícito rechazo. Pero primero tenemos que ir, en la sección siguiente, al fondo del desacuerdo entre Gadamer y Collingwood sobre la misma noción de interpretación. La teoría hermenéutica de Gadamer tiene implicaciones relativistas que están ausentes en la teoría de la interpretación de Collingwood, y nuestro argumento, en las secciones 3 a 5, consistirá en que su posición está relacionada con el problema de la distancia temporal.

\section{La distancia espacial y la recuperación de las intenciones: Gadamer vs. Collingwood}

Desde la mitad de 1930 en adelante, el arqueólogo, historiador y filósofo R.G. Collingwood ha desarrollado una teoría de la interpretación, aplicándola a la arqueología, la historia, la antropología, la estética, y la historia del arte. ${ }^{7}$

6 Este uso de la expresión "linguistic turn" (giro lingüístico) no es nuestro, no nos referimos, por supuesto, a lo que se ha tomado desde que Richard Rorty editó un libro del mismo nombre, The Linguistic Turn. Recent Essays in Philosophical Method (1967), como una de las características fundamentales de la filosofía analítica, pero fundamentales para pasar, en el interior de la filosofía de la historia en idioma inglés, de las preocupaciones sobre el concepto de "explicación" peculiar de la historia a las preocupaciones acerca de la historia como texto. En este contexto, la expresión es ambigua ya que cubre por un lado, la obra de Louis Mink, Arthur Danto, o incluso la "lógica narrativa" de Frank Ankersmit, y un "vuelco" francamente literario", un "literary turn" iniciado por Hayden White, quien importó, en la filosofía de la historia, preocupaciones de la teoría literaria, cuya fuente es en gran parte filosófica (como los escritos de Derrida) y que desde luego no son las reflexiones de los propios historiadores.

7 En una posdata a Narración y Conocimiento de Danto, Frank Ankersmit escribió: "Tal vez Collingwood nunca desarrolló una conciencia histórica porque era un arqueólogo más bien que un historiador”, que incluso describe la Idea de Historia como "superficial" con lo cual delata una "falta de sensibilidad al verdadero interés por el pasado" (Danto, AÑo: 393). "Estas son palabras inaceptablemente duras. La afirmación que Collingwood nunca desarrolló una "conciencia histórica" es, por lo menos, extrańa, visto que quería transformar la filosofía en una disciplina histórica, que reprendió a los padres de la filosofía analítica - los realistas de Oxford, John Cook Wilson, H.A. Prichard, H.W.B. Joseph— por su falta de sentido histórico, etc. (Sobre el Realismo de Oxford, ver M. Marion (2000, 2009). Que esta falta podría ser explicada por ser Collingwood un arqueólogo, como si la arqueología fuese una actividad que pudiese realizarse sin "conciencia histórica", es algo igualmente 
Desafortunadamente, murió tempranamente, a los 53 ańos de edad, sin llegar a una teoría completamente acabada. Solamente existen dos breves discusiones dedicadas a explicar estos principios: el capitulo v de su Autobiografía (1939), en la que él describió engañosamente su propia teoría como una "lógica de preguntas y respuestas", y el capítulo IV del Ensayo de metafísica (1940), mejor conocido en filosofía analítica por su noción de "presuposiciones absolutas". Hans-Georg Gadamer se encuentra entre los que estuvieron profundamente influenciados por estos textos. Para ilustrarlo, se necesita recordar simplemente que Gadamer (1989) mismo reconoció que dos de los más destacados conceptos de su hermenéutica, los de la "pre-cognición de completud" (Vorgriff der Vollkommenheit) y "fusión de horizontes" (Horizontsverschmelzung) ya estaban en Collingwood. ${ }^{8}$ Mientras este último concepto, relacionado con la noción de Collingwood de "reconstitución" ("re-enactment"), ${ }^{9}$ se refiere al resultado de la interpretación más que a su "método" putativo, ${ }^{10}$ el primero lleva un estatuto especial para Gadamer, al que llama el "axioma de toda hermenéutica" (Gadamer, 1989: 370), y en otra parte el "Urphänomen hermenéutico": "Ninguna afirmación es posible si no puede comprenderse como una respuesta a una pregunta, y las afirmaciones solamente se pueden comprender de esta manera" (Gadamer, 1976: II).

Solamente necesitamos resaltar que la afirmación es una conjunción, cuya primera parte ya se expresa en Un ensayo de metafisica: "Toda afirmación que cada uno hace se basa sobre una respuesta a una pregunta" (Collingwood, I940: 23).

Mientras que la segunda parte fue expresada un año antes en su Autobiografía:

Usted no puede entender lo que uno quiere decir simplemente al estudiar sus afirmaciones habladas o escritas, aun si ha hablado o escrito con un perfecto dominio del lenguaje y una intención perfectamente verdadera. Con el fin de entender su significado, usted debe saber cuál era la pregunta [...] por la cual lo que se escribió o se dijo se pensó como una respuesta (Collingwood, I939: 31).

extraño (sobre todo en el caso de Collingwood), pero la afirmación que no era un historiador es totalmente falsa. Contrariamente a muchos de sus detractores, Collingwood escribió realmente libros de historia, cuyo contenido excede de lejos la mera interpretación de datos a partir de excavaciones arqueológicas y la interpretación de una acción puntual de un solo individuo, como César cruzando el Rubicón. Ver, por ejemplo Collingwood (I932) o Collingwood y Myres (1936). Por supuesto, todo depende de cómo se defina la "conciencia histórica", pero si se la entiende como sensibilidad a la distancia temporal, entonces esperamos que nuestro trabajo proporcione una réplica. Ankersmit (1986), desgraciadamente, no es ajeno a las afirmaciones absurdas sobre Collingwood.

8 La "pre-cognición de completud" se halla introducida (Gadamer, 1989: 293-294), y la "fusión de horizontes" (Gadamer, 1989: 306).

9 La "reconstitución” (“Re-enactment") se introduce por primera vez en, Collingwood (1928). Véase también el conocido pasaje en (Collingwood, Idea of History, 215) y en (Collingwood, Idea of History, 282f.) para una discusión más detallada.

10 Las diferencias entre la "fusión de horizontes" de Gadamer y la "reconstitución" de Collingwood, son, sin embargo, sustanciales, pero no pueden ser discutidas aquí. Véase (Stueber 2002). 
Los paralelos se extienden más allá, pero no es el lugar para más discusión al respecto. Lo que sigue, sin embargo, debería ser suficiente para mostrar lo cercanos que están estos dos filósofos.

Como la mayor parte de sus admiradores, Gadamer hizo su parte para promover a Collingwood: tenía una traducción de Una Autobiografía publicada en los años I950 bajo el titulo Denken. Eine Autiobiographie, ${ }^{\text {II }}$ para la cual escribió una introducción y dedicó, también, a Collingwood una sección que conforma la segunda mitad de un capítulo clave de Verdad y Método, titulado "La prioridad hermenéutica de la pregunta", al comienzo del cual Gadamer afirma que "la lógica de las ciencias humanas es una lógica de la pregunta", añadiendo en seguida que: "A pesar de Platón, no estamos muy preparados para este tipo de lógica. Casi la única persona a la que encuentro con un vínculo con ella es $\mathrm{R}$. G. Collingwood" (Gadamer, 1989: 370).

Cualquiera que sepa la importancia de Platón en el pensamiento de Gadamer se da cuenta de que esto va más allá de una banal alabanza. De hecho, la primera parte de este capítulo está dedicada a Platón sobre los "juegos dialécticos", un tipo particular de diálogos que proceden por pequeñas preguntas y respuestas, habitualmente conducidos por Sócrates, un tema que nos remonta a su Habilitationsschrift en los años 1930, La Ética dialéctica de Platón (Gadamer, 199I). ${ }^{\text {I2 }}$ (Vale la pena tomar en cuenta que la influencia de Collingwood se siente en un sector del pensamiento de Gadamer en el que la omnipresencia de Heidegger se siente menos). En su introducción a Denken, Gadamer también escribió:

Para el lector alemán, para quien Collingwood era hasta el día de hoy totalmente desconocido, la aparición de la Autobiography en una traducción alemana significa mucho. Con un estilo sorprendente y enigmático, este escritor foráneo no es foráneo y cuando empieza a hablarnos en alemán es casi como alguien que vuelve a su hogar, como alguien quien, a pesar de vivir y trabajar en el exterior, nunca olvidó su hogar espiritual. Su patria es la amplia extensión del romanticismo alemán y de la escuela histórica — Hegel, Schelling, Humboldt, Ranke, Droysen, Schleiermacher y Dilthey [...] Collingwood está en casa en esta tradición [...] (Gadamer, 1992: 9).

La tradición hermenéutica en Alemania tiene su canon, con los autores enumerados aquí por Gadamer, y uno puede entender este pasaje como un intento por cooptar a Collingwood en este canon. Desgraciadamente, si esa fue su intención,

II R. G. Collingwood, Denken. Eine Autobiography (Stuttgart, K. F. Koehler Verlag, I955). Gadamer señala su papel en Truth and Method, 370, n. 315.

I2 Sobre los juegos dialécticos en La Academia, ver: Castelnérac y Marion, "Arguing for Inconsistency: Dialectical Games in the Academy”, 2009. La caracterización más formal del mecanismo lógico que resalta estos juegos dialécticos difiere, en este ensayo, de la de Gadamer, con diferentes consecuencias filosóficas. 
se tiene que concluir que ha fallado; casi ningún lector de Gadamer toma en serio a Collingwood. Parte de las razones de esto, vienen del propio juicio de Gadamer sobre el lugar de Collingwood en este canon. En el mismo texto describió la filosofía de Collingwood como "un extraño y exótico género de historicismo" (Gadamer, 1992: 9). Dicho de otra forma, Gadamer ha clasificado simplemente a Collingwood entre uno de los historicistas románticos, quizás en su mente más cercano a Dilthey. Aportó también argumentos contra lo que percibió, sobre la base de su encasillamiento, como debilidades de la posición de Collingwood, que no podemos discutir aquí por razones de espacio. ${ }^{13}$

Todo esto tuvo como efecto ocultar la deuda de Gadamer con "la lógica de preguntas y respuestas" de Collingwood, y, peor aún, su juicio sobre el autor inglés es sans appel: la dimensión de la meditación hermenéutica que pasa a través de todo acto de comprensión aún se le escapa (Gadamer, 1989: 516).

Es difícil desentrañar la red de razones de esta afirmación, y vamos a dejar fuera enteramente, en lo que sigue, el asunto del supuesto historicismo de Collingwood para concentrarnos en una idea obvia, a saber, la posibilidad de recobrar la intención de un agente o un autor. Según Gadamer, no es solamente imposible, es además un error concebir una "comprensión" en términos de un intento de hacerlo, porque el significado de un texto siempre va más allá de su significado intencional. Por lo tanto, "comprender" es siempre en cierto modo "productivo" o "creativo": "No solo ocasionalmente sino siempre, el significado de un texto va más allá de su autor. Es así que comprender no es meramente una actividad reproductiva sino siempre una actividad" productiva (Gadamer, 1989: 296, las cursivas son nuestras).

Gadamer tiene una manera elegante de decir esto, a saber, que "comprender" es siempre "comprender de diferente manera" (Gadamer, 1989: 372). Así, el intérprete debe buscar solamente el significado de un texto y no el significado intencional del autor:

Nuestra comprensión de la tradición escrita per se no es tal que podamos simplemente presuponer que el significado que descubrimos en ella concuerda con la intención de un autor [...] el sentido de un texto, en general, llega mucho más allá de lo que un autor originalmente quiso decir. La tarea del comprender se refiere sobre todo al significado del texto mismo (Gadamer, I989: 372).

Como era de esperar, Gadamer extiende estas conclusiones a las intenciones de los agentes históricos: "La reducción hermenéutica al significado del autor

I3 Hemos encontrado sólo dos en Gadamer (1989). Estos argumentos específicos se tratarán en un próximo trabajo que será titulado "Revisiting Gadamer's Critique of Collingwood's 'Logic of Questions and Answers”. 
es tan inapropiada como la reducción de los eventos históricos a las intenciones de sus protagonistas (Gadamer, 1989: 373).

Este paso tiene un precio en el caso de Gadamer, porque parece ser culpable de confundir el significado histórico o el "significado histórico-mundial" de los eventos, que de hecho se desarrolla a lo largo del tiempo con repercusiones muchas veces no previstas por los actores mismos, con una explicación racional o práctica de dichas acciones en términos de sus intenciones, por ende, con su comprensión de la situación en la que dichos actores han tenido que actuar: explicar las razones de las acciones de un agente no tiene nada que ver con no haber previsto algunas o todas las consecuencias históricas no deseadas. ${ }^{14}$ No quisiéramos insistir más adelante con este punto. Basta con subrayar que, por otro lado, Collingwood cree en poder capturar los pensamientos de los agentes históricos y, por lo tanto, asigna esta tarea al historiador:

[...] el historiador debe ser capaz de pensar de nuevo para sí mismo el pensamiento cuya expresión está tratando de interpretar [...] Lo importante aquí, es que el historiador de un pensamiento particular debe pensar para él mismo este mismísimo pensamiento, y no otro similar (Collingwood, I939: III).

Collingwood quiso decir esto literalmente. Refiriéndose a la frase famosa de Nelson durante la batalla de Trafalgar, "en honor les gané, en honor moriré con ellos", escribió: "El pensamiento de Nelson, tal como Nelson lo ha pensado y tal como lo re-pienso, es con seguridad uno solo, un mismo pensamiento" (Collingwood, 1939: II2).

Regresaremos a este importante punto más adelante, sólo hace falta por el momento que uno se de cuenta que ésta parece ser la razón por la cual Gadamer afirma en última instancia, en la cita de arriba, que la "dimensión de la mediación hermenéutica que pasa a través de cada acto de comprensión se le escapa a Collingwood" (Gadamer, 1989: 516).

Con esto volvemos a lo que hemos descrito anteriormente como uno de nuestros más arraigados prejuicios, junto a los cuales se encuentra Gadamer, mientras que las afirmaciones de Collingwood, por lo general, sirven como razones para despacharlo sin más preámbulos, incluso antes de saber si vale la pena tratarlo. Como hemos dicho, vamos a examinar el papel del modelo intuitivo del tiempo al formar aquel prejuicio en el pensamiento de Gadamer, y en la tentativa de Collingwood de combatir este último por socavar el primero. Nuestra mejor entrada en este asunto será a través de lo que llamamos el "problema de la transposición".

I4 La confusión ocurre en Gadamer (I989), en un pasaje donde critica a Collingwood. No lo podemos discutir aquí en detalle, pero trataremos este tema en el documento mencionado en la nota $24 \mathrm{a}$ 


\section{El problema de la transposición}

Para generar el problema, se puede simplemente apelar al modelo intuitivo del tiempo. Supongamos que tenemos la tarea de comprender el pensamiento de, digamos, Platón, quien sabemos que vivió y escribió en la Antigua Grecia, aproximadamente 2400 años atrás, y que escribió en una lengua que se extinguió hace mucho - pero tenemos que dejar de lado la cuestión del relativismo cultural que se podría plantear aquí. Según este modelo, el contexto de Platón se encuentra a una distancia considerable en el tiempo de nosotros. ¿Cómo se puede pasar por encima de este abismo? Como lo plantea el famoso motto de Wilhelm Dilthey, de su Beiträge zum Studium der Individualität (I895/96): "Reconstruir es revivir" (Dilthey, 1924: 277). Así, su respuesta era que el historiador debía "transponerse" a sí mismo, en lugar de "revivir" literalmente los pensamientos de Platón: "[...] desde la plenitud de nuestra experiencia propia, la experiencia fuera de nosotros se reproduce y se comprende a través de la transposición" (Dilthey, 1924: 263, Citado en Habermas, 1978: 146).

El problema que salta a la vista con esta respuesta, con la que Dilthey no se mantuvo mucho tiempo satisfecho, es que el historiador se transpone él mismo en el pasado o que el pasado se transpone en el presente, y ninguna alternativa parece correcta: es efectivamente dudoso que el historiador pueda transponerse él mismo, ya que no le es posible librarse enteramente de sus propios prejuicios (un punto sobre el que Gadamer insiste fuertemente), mientras que si todo está ocurriendo en el presente del historiador, entonces éste se encuentra bajo cierta ilusión acerca de revivir realmente el pasado: sería más bien que el pasado reconstituido es solamente una proyección del presente, y que el historiador está bajo una ilusión. La afirmación es que Dilthey no puede evitar los cuernos de este dilema. Tenemos que notar, en cambio, de qué manera la distancia temporal se involucra en este argumento: es precisamente porque hay un abismo temporal - o espacial en este caso- para hacer el puente entre el historiador y Platón, que se tiene que hablar con Dilthey de una "transposición". En otras palabras, no necesitaríamos de una transposición si no hubiese un abismo. Desde este "punto de vista monadológico de la hermenéutica", para usar las palabras de Jürgen Habermas (1978), es así como se genera un dilema: o bien el historiador termina en los zapatos de Platón, aproximadamente hace 2400 años, o Platón no es más que pensamientos en la mente del historiador. ¿Cuál es la respuesta? Ninguna parece satisfactoria. Es lo que llamamos el "problema de la transposición”. Tenemos que ver ahora cómo Gadamer y Collingwood lo tratan.

En el capitulo histórico introductorio de la parte in de Verdad y Método, Gadamer desarrolla una crítica de la "hermenéutica romántica", describiéndola 
como habiéndose apartado del pleno desarrollo en Hegel de la "filosofía reflexiva", una regresión que dice haber forzado toda una tradición a entrar en un dilema ineludible: sea recurrir a la psicología individual, sea apelar a la significación histórica. Dicho de otra forma, caemos en el psicologismo o necesitamos de la filosofía de la historia de Hegel. Para Gadamer, recurrir a Hegel era inevitable ya que toda esta tradición no podía ir más allá de los "cuadros elaborados por el idealismo de Hegel” (Gadamer, 1987: 92; Gadamer, 1989: 34I). Sólo con la crítica de Heidegger del concepto de experiencia de Hegel, nos dice, somos finalmente capaces de sobrepasar las "limitaciones de la filosofía reflexiva" (Gadamer, 1989: 34I). Parafraseando el título de un capítulo de Verdad y Método, Dilthey, al parecer, sigue estando "atrapado" en las "aporías" del historicismo (Gadamer, 1989: 2I8); se presenta en consecuencia como oscilando entre el psicologismo de sus primeros escritos, entre los que acabamos de citar, y las nuevas referencias al "Espíritu objetivo" de Hegel en sus últimos manuscritos, como en Der Aufbau der geschichtlichen Welt in den Geisteswissenschaften (Dilthey, 1927). No queremos plantear aquí las cuestiones relativas a la idoneidad de la utilización de las grandes narrativas de este tipo en la historia de la filosofía. Basta con decir, en nombre de Gadamer, que aunque la dificultad original de Dilthey tiene que ver con su confianza en la psicología, para hablar como lo hizo después de, por ejemplo, "la reconstrucción de una objetivación mental", como opuesta a "volver a vivir toda una estructura psíquica”, pensándolo bien, en realidad no obtenemos una solución más cercana de tal problema de la transposición.

En términos estratégicos amplios, la solución de Gadamer tiene que ver con su larga crítica al descrédito lanzado por la Ilustración sobre los "prejuicios" — "Vorurteile", en el sentido peculiar de Gadamer, más cerca de "presuposiciones" (Gadamer, 1989: 27I). El punto de Gadamer era que no teníamos derecho a deshacernos de las tradiciones como simples fuentes de prejuicios, en el sentido negativo de la palabra, sino que debemos abrazarlas, para restablecer la autoridad y la tradición, porque abren el camino al sentido de un texto. Si una voz como la de Platón nos hablase desde el pasado sería a través de una tradición de interpretación de su texto. La clave para Gadamer aquí es el punto de vista positivo de Heidegger de la tradición por entregarnos una "deuda" (Schuld), que forma la realidad histórica de uno mismo. En efecto, Gadamer, que alude aquí a la famosa frase de Ranke, confía fuertemente en Heidegger para fundamentar su afirmación:

'Pertenecer' es una condición del significado original de interés histórico no sólo porque la elección de un tema y la investigación está sujeta a motivaciones extra-científicas, subjetivas [...] sino porque pertenecer a tradiciones pertenece no más que, original y 
esencialmente, a la finitud histórica del Dasein tal como lo hace su propia proyección hacia posibilidades futuras de sí mismo. [...] De esta manera, no hay comprensión o interpretación en las que la totalidad de esta estructura existencial no funcione, aunque la intención del conocedor sea simplemente de leer "lo que hay" y descubrir a partir de sus fuentes 'lo que realmente ocurrió (Gadamer, I989: 262).

Entonces, los prejuicios legados por la tradición constituyen la realidad propia del historiador (Gadamer, 1989), y tienen que ser aceptados como tal, ya que los prejuicios no reconocidos van seguramente a causar distorsiones en la comprensión de un texto.

En un capítulo importante de "La recuperación del problema hermenéutico fundamental", Gadamer presenta su solución a lo que llama el "problema de la aplicación", en términos de las tradiciones de la hermenéutica jurídica y teológica. En pocas palabras, y en un modo mucho más simple, su afirmación clave consiste en que un texto de una ley dada es reinterpretado de nuevo por el juez, en cada ocurrencia de su aplicación, desde luego que cada nueva interpretación del texto provoca un nuevo significado que va a tener un efecto sobre la historia mientras ese nuevo significado se implemente, y así sigue. Así hemos vuelto a las ideas previamente citadas en la sección previa, según las cuales toda interpretación de un texto es "productiva", crea una capa de significado, y se vuelve imposible así reapropiarse de la intención del autor ya que se encuentra enterrada bajo esas capas, por así decir. Aquel proceso es, por supuesto, abierto, infinito, ${ }^{15}$ pero no es, para usar una metáfora matemática, convergente a un límite. Otro corolario es que el texto adquiere su significado con el tiempo, en analogía con la significación histórica de un evento como la batalla de Trafalgar, de la que no se puede decir que había sido prevista por los agentes implicados en ella, sino que se había desplegado durante las décadas y siglos que siguieron. Pero Gadamer no ve la tradición como un obstáculo entre nosotros y el texto, la ve más bien de manera positiva como una especie de conducto entre nosotros y el texto:

I5 Como Gadamer lo expresa: "[...] el descubrimiento del verdadero significado de un texto o de una obra de arte nunca se termina, de hecho es un proceso infinito” (Gadamer, 1989: 298). Una vez más habría que notar un paralelo con Collingwood (1993), quien también sostuvo esta tesis acerca de la historia, así como por el arte y el idioma:"[Un público] no tiene porqué [...] pensar que ha extraido 'el' significado de la obra [de arte], porque no hay tal cosa.[...] La doctrina de la pluralidad de significados, expuesta para el caso de la Sagrada Escritura por Santo Tomás de Aquino, es en principio absolutamente sana: como él lo afirma, el único problema es que no va lo suficientemente lejos. En una forma u otra, eso es cierto para todos los idiomas" (Collingwood, I938: 3II). Esta última afirmación parece, a primera vista, contradecir las afirmaciones de Collingwood sobre la posibilidad de reconstituir idénticamente la idea de un agente histórico, pero no podemos discutir este punto aquí. 
Así pues el significado de "pertenecer" -i.e., el elemento de la tradición en nuestra actividad histórica-hermenéutica-, se cumple en lo común de lo fundamental, activando los prejuicios. La hermenéutica tiene que empezar con la posición de una persona buscando comprender algo que está vinculado al tema que viene en el lenguaje a través de un texto de la tradición y tiene, o adquiere, una conexión con la tradición desde la que habla el texto (Gadamer, 1989: 295).

Añadiéndose a ello un llamado crucial a la noción de tiempo "auténtico" o "temporalidad" de Heidegger (sobre ello, hay más en la sección 5), tenemos todos los elementos para la solución propia de Gadamer para el problema de la transposición:

El tiempo ya no es más un abismo ante todo para cruzar porque está separado; de hecho, es el suelo de apoyo en el curso de los eventos en el que el presente está arraigado. Por lo tanto la distancia temporal no es algo que hay que superar. Esto era, más bien, la suposición ingenua del historicismo, a saber que nos transportamos a nosotros mismos en el espíritu de la época, pensamos con sus ideas y pensamientos, no con los nuestros, y desde luego avanzamos hacia la objetividad histórica. De hecho, lo importante es reconocer la distancia temporal como una condición positiva y productiva haciendo posible la comprensión (Gadamer, 1989: 295).

En el contexto de este ensayo, uno necesita ver que Gadamer está lejos de rechazar nuestro modelo intuitivo del tiempo. Al contrario, lo integra claramente, puesto que ve la "distancia temporal" como la clave de la solución para el problema de la transposición.

En su visión del asunto, desde el momento en que Platón escribió en adelante, existe una serie de interpretaciones organizadas cronológicamente, cada una de ellas trayendo una nueva capa de significado como respuesta a los prejuicios entonces existentes, pero que nos sirven como un conducto por el que alcanzamos el texto, con el fin de plantear nuestras preguntas, según nuestros propios ineludibles prejuicios, aun después de desmontar algunos de ellos. Sin embargo, al estar en una distancia, al otro extremo de la serie, la intención original del autor de un texto es, como vimos, no reapropiable, y Gadamer hasta da a entender que no es ni siquiera el objetivo de la hermenéutica de ensayar y reapropiarse de ello. Nos preguntamos naturalmente si recobrar la intención de un autor es problemático solamente en el caso, por ejemplo, de los textos de Platón, pero no a lo largo de la tradición que nos los hizo llegar hasta nuestros días. Si, no obstante, este fuera el caso, lo cual sería problemático para toda la tradición (¿para el propio Gadamer?), tendríamos entonces un argumento de regresión infinita en nuestras manos, y sería entonces difícil ver bajo qué condiciones la tradición pudiese ser 
vista positivamente. No sabemos qué posible respuesta hubiera dado Gadamer a este problema, pero notamos la tendencia, inducida por el modelo intuitivo del tiempo y el problema de la distancia temporal, de pensar que, cuanto más lejos un texto esté en el tiempo, tanto más difícil pensamos estar de entender lo que su autor quiso decir: se nos dice entonces que ni siquiera hay que intentarlo. Pero, con todo - y poniendo aparte por un momento todo asunto clave respecto de lenguaje y cultura: ¿Platón es realmente más difícil de entender que Heidegger? ¿La distancia temporal es realmente el factor clave aquí? ¿Tendría siquiera que jugar un papel?

Collingwood estaba totalmente consciente del problema de la transposición, gracias a su lectura de varios autores incluyendo a Dilthey, pero también a otros como a Georg Simmel, y a su propio contemporáneo Michael Oakeshott. ${ }^{16}$ En efecto, podemos leer un pasaje que vale la pena citar en su totalidad en la sección sobre Dilthey en The Idea of History de Collingwood:

Dilthey y Simmel han escogido, de hecho, dos cuernos opuestos del mismo falso dilema. Cada uno realiza que el pasado histórico, esto es, la experiencia y los pensamientos de los agentes cuyos actos estudia el historiador, tiene que volverse parte de la experiencia personal propia del historiador. Cada uno, luego, puede argumentar que esta experiencia, porque es la suya, es puramente privada y personal, una experiencia inmediata dentro de su propia mente, $y$ nada objetiva. Cada uno ve que tiene que ser algo objetivo si tiene que ser un objeto del conocimiento histórico. ¿Mas cómo puede ser objetivo cuando está puramente subjetivo? ¿Cómo puede ser algo conocible si se trata de un estado de la mente? Simmel dice, al proyectar esto hacia el pasado: con el resultado de que la historia se vuelve la pura proyección ilusoria de nuestros propios estados de la mente ante la pantalla en blanco del pasado desconocido. Dilthey dice, al volverse el objeto del análisis psicológico: con el resultado de que la historia desaparece en conjunto y está reemplazada por la psicología. La respuesta a ambas doctrinas es que puesto que el pasado no es un pasado muerto, sino que sigue vivo en el presente, el conocimiento del historiador no está expuesto para nada a ese dilema: no es ni un conocimiento del pasado y asimismo tampoco un conocimiento del presente, u otro conocimiento del presente y asimismo tampoco un conocimiento del pasado; es un conocimiento del pasado en el presente, el conocimiento de sí mismo de la mente propia del historiador como el presente resucitado y la reapropiación de más experiencias del pasado (Collingwood, 1993: 174-175).

I6 La lectura de Collingwood (I993) de M. J. Oakeshot (I933) lo había hecho muy consciente del primer cuerno del dilema, enfrentado por Simmel. Esto es, en efecto, esencialmente la postura adoptada también por Oakeshott. Por la crítica de Collingwood Idea of History (1993). 
Aunque la formulación difiera considerablemente, se puede reconocer fácilmente el problema de la transposición en el "dilema" de Collingwood. No podemos leerlo asimismo como habiendo fundado, sin darse cuenta, el mismo dilema que Dilthey. Antes de explicar cuál pudo haber sido su solución a este problema, vale la pena señalar otras razones para no seguir a Gadamer y encasillar la filosofía de Collingwood como "hermenéutica romántica". Existen, de hecho, otras razones, quizás más conocidas, para no confundir a los filósofos.

Primero, la noción de Collingwood de "reconstitución" ("re-enactment") difiere de la "Nacherleben" de Dilthey, y otras nociones afines psicologistas tal como la de "Einfüblung", precisamente en ello que no se trata de una actividad meramente pasiva sino activa, crítica:

No es una sumisión pasiva al llamado de la mente de otro; es una labor de un pensamiento activo y desde luego crítico. El historiador no solamente reconstituye (re-enacts) el pensamiento pasado, sino que lo reconstituye (re-enacts) en el contexto de su propio conocimiento $\mathrm{y}$, desde luego, al reconstituirlo (in re-enacting it), lo critica, forma su propio juicio de su valor, corrige todo error que pueda discernir en aquél. Este criticismo del pensamiento cuya historia él rastrea, no es algo secundario al rastreo de la historia de ello. Es una condición indispensable del conocimiento histórico mismo. Nada puede estar en más completo error respecto de la historia del pensamiento que el suponer que el historiador como tal acierta meramente 'este-yotro-pensamiento', [...] (Collingwood, I993: 215).

La razón profunda de aquello proviene del hecho que Collingwood ve al historiador desde el modelo del detective, como Sherlock Holmes, ${ }^{17}$ al inferir sobre las bases de las huellas dejadas detrás lo que efectivamente ha sucedido. Tales inferencias manejan siempre una dimensión crítica, de manera muy clara. Para tomar un ejemplo muy sencillo, al discutir el rápido estudio de las costas británicas cerca de Dover, con el objetivo de encontrar una ubicación adecuada para los ejércitos de César para hacer un desembarque en 55 A.C., que lo guió a elegir una playa apartada cerca de Deal, Collingwood comenta que César se perdió de descubrir, por unos kilómetros, el puerto de Richborough, con consecuencias casi catastróficas (porque una tempestad casi arrasó la flota sin protección del César, evitando así, temporalmente, un posible retiro), este comentario crítico es posible, simplemente, porque el historiador tiene la ventaja de la retrospectiva y, en este caso, un conocimiento geográfico mejor que los agentes históricos (Collingwood y Myres, 1936).

En un segundo lugar, Collingwood desarrolla un modelo de la mente en términos de niveles, desde un puro flujo de sensaciones (y emociones concomi-

I7 Ver, por ejemplo, el cuento "Quién mató a John Doe?" y su análisis en Collingwood (1993). 
tantes) hasta una elección racional, que nos lleva a realizar nuestro deber, una versión simplificada de ello podría verse así: ${ }^{18}$

Elección

(Desde el capricho a la elección racional)

Segundo nivel de conciencia

(Emociones de orden superior y deseos)

Primer nivel de conciencia o "awareness"

Flujo de emociones o sensaciones

Según él, todo lo que sucede en el nivel inferior — para él, la esfera propia de la psicología - nunca sucede otra vez exactamente igual, y desde luego, no puede ser "re-creado" (Re-Enacted). Sólo cuando nos volvemos conscientes (a través del lenguaje) de alguna sensación o emoción, es solamente al "primer nivel de conciencia” que el pensamiento, en principio, es público y accesible (aun si se guarda su pensamiento para sí mismo), así en principio puede ser "re-creable". ${ }^{\text {Iq }}$ Es lo importante, desde luego, de la "re-constitución" (Re-Enactment) de "revivir" plenamente, en cualquier sentido psicológico que vino a la mente de Platón, cuando escribió, por ejemplo, el Teeteto, así que no hay ningún lugar para un psicologismo desarrollado, por ejemplo, en los escritos tempranos de Dilthey. ${ }^{20}$ Dejando a un lado el modelo peculiar de la mente usado por Collingwood en su argumento, el paso va a ser familiar para los lectores de las tradiciones fenomenológicas y analíticas como Sir Michael Dummett lo caracterizó, en el capítulo 4 de Orígenes de la filosofía analitica, como "la extrusión de los pensamientos de

I8 Su última y más interesante presentación de esta idea aparece en el capitulo introductorio de R.G. Collingwood, The New Leviathan (1992). Para un comentario, ver L/O. Mink, Mind, History, and Dialectic: The Philosophy of R.G. Colingwood (1969).

I9 Collingwood deja claro que "re-enactment" no implica una reconstitución del flujo de las sensaciones y sus emociones que las acompañan, sino que forma la base de la conciencia de cada uno porque, una vez que se fue, no puede ser revivida. Sus ejemplos son "How flowers smelt in the garden of Epicurus", "How Nietzsche felt the wind in his hair as he walked on the mountains", "The buoyancy of Archimedes' body in the bath" (Collingwood, I993: 296 y 298).

20 En realidad, Collingwood era un crítico muy severo de la psicología como una disciplina, precisamente porque creía que, con los métodos de las ciencias de la naturaleza, la psicología se limitó al estudio del nivel básico del flujo de la sensación, y se pondría al borde de la pseudo-ciencia si intentara estudiar niveles superiores del pensamiento, donde la ciencia debe ser "normativa” y, como él lo decía, "criteriológica" (Collingwood, I938: I7In.). Sobre la crítica de Collingwood de la psicología, que está más elaborada en An Essay on Metaphysics (1940) y The Principles of History and other Writings in the Philosophy of History (1999), véase J. Connelly y A. Costall (2000). 
la mente" (Dummett, I993: 22-27) uno de los pasos por el que Frege y Husserl son muy famosos. ${ }^{21}$

Estos dos puntos deben haber sido suficientes para no confundir la posición de Collingwood con la de Dilthey, pero Gadamer, que no tiene sino comentarios expeditivos sobre la sección de The Idea of History dedicada a Dilthey, describiéndola como "muy decepcionante" y "casi ininteligible para un lector de otra nacionalidad", parece haberles pasado por alto (Gadamer, I989: 514)..22 El segundo era, como lo veremos, un paso bastante crucial.

\section{Rechazando el modelo intuitivo del tiempo}

El lenguaje en el que las enmarcó, hace las ideas de Collingwood difíciles de comprender. He aquí dos ejemplos. Primero, Collingwood distingue entre lo "interior" y lo "exterior" de un evento pasado, como "acciones" —el propio tema de la historia — son para él eventos con un "interior":

El historiador, al investigar cualquier evento en el pasado, hace una distinción entre lo que puede ser llamado el afuera y el adentro de un evento. Por el afuera de un evento quiero decir todo lo que pertenece a ello que puede describirse en términos de cuerpos y de sus movimientos: el paso del César, acompañado por ciertos hombres, por un río llamado el Rubicón en cierta fecha, o el derrame de su sangre sobre el piso de la casa del senado en otra fecha. Por el adentro de un evento, quiero decir el que sólo puede describirse en términos de pensamiento: la desconfianza del César por la ley de la República, o el choque de la política constitucional entre él mismo y sus asesinos. Su trabajo empezaría al descubrir el afuera de un evento, pero nunca puede terminar aquí; tiene que recordar siempre que un evento fue una acción, y que su tarea principal es de pensar él mismo en aquella acción, discernir el pensamiento de su agente (Collingwood, I993: 213).

El "afuera" de un evento lo define aquí como su descripción física, mientras que el "adentro" es la descripción del mismo evento desde lo que deberíamos

2I Esta conexión podría sorprender a más de un lector, porque Frege y Husserl son interpretados a menudo, incluso por Dummett (ver la nota anterior), como habiendo seguido los pasos de Bolzano. Sería menos sorprendente si se tuviese también en cuenta el papel histórico de Hermann Lotze: un movimiento análogo ocurre en su descripción de la teoría platónica de las ideas en el capítulo ir del Libro III de su Logic (I884), que no sólo influyó a Husserl, como lo dice él mismo, y, si debiéramos estar de acuerdo, por ejemplo, con Gottfried Gabriel (1986), a Frege, sino también a F. H. Bradley, cuyo "idealismo objetivo" deriva quizás aún más de Lotze que de Hegel, y realmente forma la tela de fondo de Collingwood. Sobre este último punto ver M. Marion (2009).

22 La reacción de Gadamer es sin embargo comprensible, puesto que Collingwood no habla de la evolución de Dilthey hacia sus puntos de vista posteriores, bajo la influencia de Husserl. Este es un capítulo importante de la tradición hermenéutica. 
llamar ahora un punto de vista "intencional" (aunque él a penas usa este término). Collingwood ha sido acusado de introducir una forma desacreditada de dualismo cartesiano de la mente y la materia, ${ }^{23}$ pero su afirmación es puramente que hay tan sólo un evento con (al menos) dos descripciones y análisis posibles de ello, un poco como uno habla desde G.E.M. Anscombe (I957) de una acción siendo intencional "bajo una descripción". Como él escribió en The New Leviathan: "Porque el cuerpo de un hombre y la mente de un hombre no son dos cosas diferentes. Son una sola y misma cosa, el hombre mismo conocido de dos maneras diferentes" (Collingwood, I992: 2.43).

Por otra parte, Collingwood escribe también de manera críptica: "Después de que el historiador ha recolectado los hechos, ya no hay más proceso de investigación en sus causas. Cuando conoce lo que ha sucedido, ya conoce por qué ha sucedido". (Collingwood, I993: 214).

Como resulta, sin embargo, Arthur Danto puso el mismo punto en un motto muy famoso: "la historia es de toda una sola pieza" (Danto, 2007: II5). Esta idea simplemente quiere decir que nunca en la historia hay una pura descripción del "afuera" de un evento, sin una interpretación en términos de su "adentro", esto es desde una visión intencional.

Estas dos descripciones del mismo evento vienen estrechamente ligadas con sus propias presuposiciones (Collingwood, I992: 2.4I, 2.45). Collingwood ha insistido también sobre lo que llamó la "idealidad de la historia” (Collingwood, I993: 440). ${ }^{24}$

Con esto simplemente quiso decir que los eventos que están ocurriendo son "actuales", mientras que los eventos que han ocurrido simplemente no lo son; por eso, los llamó “ideales". El background "idealista” de Collingwood entra en el juego al escoger esta palabra: después de todo, los eventos pasados se dicen "ideales" en el sentido en que inferimos "en nuestras mentes", por así decir, lo que pasó. Por lo tanto, no sólo para él "toda historia es la historia del pensamiento" (Collingwood, I993: 215), lo es también "en el pensamiento", incluso "en el pensamiento actual”. Concluir que la posición de Collingwood es una forma de "idealismo" implicaría, sin embargo, una grave distorsión de su visión de las cosas: estamos hablando del mismo evento bajo dos descripciones, y Collingwood no está haciendo una afirmación metafísica de la realidad física del evento en sí, según la cual sólo estaría "en la mente del historiador". Este es un error cometido por Paul Ricoeur, cuando éste atribuye a Collingwood, en los pasajes que se discutirán en la sección 5 , la afirmación de que el pasado no

23 Por ejemplo por Patrick Gardiner (1952).

24 Esto está tomado de un manuscrito importante publicado en la edición revisada de The Idea of History.. 
sobrevive fuera del acto de "re-creación" (Ricoeur, I984, I988). Collingwood se limita a afirmar que la descripción intencional conforme a la cual el historiador estudia eventos “ideales", presupone en cambio una noción diferente del tiempo "físico" ordinario.

La razón de esto no es difícil de encontrar. Mientras que el flujo "físico" del tiempo está presupuesto en el caso de explicaciones causales, una explicación de un evento conforme a su descripción intencional sería semejante a lo que nosotros llamaríamos una explicación racional, donde el explanans no va a ser el antecedente temporal de la acción; es su "Grund" ${ }^{25}$ Collingwood expresa el pensamiento como sigue:

En cierto sentido, estos pensamientos son, sin duda, ellos mismos eventos que suceden en el tiempo: pero como la única manera por la cual el historiador puede distinguirlos es re-pensándolos para sí mismo, hay otro sentido, y muy importante para el historiador, en el que no se encuentran en el tiempo, en absoluto. [...] la peculiaridad que hace que [un pensamiento] sea histórico no es su acontecer en el tiempo, sino el hecho que se haga conocer a nosotros a través de nuestro re-pensar el mismo pensamiento que creó la situación que estamos investigando, y así llegar a entender esa situación (Collingwood, 1993: 218).

Para entender este punto es necesario recordar aquí la "extrusión de los pensamientos de la mente", que atribuimos a Collingwood: razones, intenciones o motivos para la acción, cuando se integran en una explicación racional, no pertenecen a la mente, si lo que queremos decir aquí por "mente" realmente va dentro de un recipiente tal como nuestro cráneo, con una ubicación espaciotemporal precisa, cuando uno recorre los pasos de esa explicación. Permaneceríamos aquí dentro del flujo "físico" de tiempo, presupuesto de las explicaciones causales. Un argumento estándar fue proporcionado tanto por Frege como por Husserl: si no fuera así, entonces habría tantos, digamos, teoremas de binomios

25 Esto plantea la cuestión de la distinción entre causas y razones y la distinción concomitante entre explicaciones causales y racionales. Collingwood parece comprometido a una distinción estricta - las explicaciones racionales no pueden ser explicaciones causales - mientras que la historia convencional dice que Donald Davidson (200I) dio argumentos decisivos contra ella en su artículo, "Actions, Reasons and Causes" publicado por primera vez en 1963. Véase G. D’Oro, (2007). No hay lugar para discutir este complejo conjunto de cuestiones, sólo quisiéramos señalar que lo que acaba de llamar la "historia convencional" sobre Davidson ya implica una distorsión de sus puntos de vista, sobre este punto, véase F. Stoutland (20II). Además, cabe señalar que los defensores de una estricta distinción, tales como Georg Henrik von Wright, para quien no se puede decir, pues, que las acciones humanas tengan causas, restringen sus afirmaciones a un sentido estricto de la palabra "causa"—véase, por ejemplo. G.-H. von Wright (I97I) — mientras Collingwood distingue en los capítulos XxIX-XxxiI de An Essay on Metaphysics tres sentidos de "causa" con el fin de delimitar un sentido "histórico" particular bajo el cual se puede decir legítimamente que las acciones humanas son causadas. Así, correctamente entendidos, Collingwood y Davidson no están tan lejos como a menudo se los presenta. 
como hay pruebas individuales del teorema de Newton en mentes diferentes. ${ }^{26}$ Collingwood tiene el mismo argumento, ${ }^{27} \mathrm{e}$ incluso añade:

Para una cierta reconstitución es posible [...] y si el oponente dice que ningún tipo de reconstitución es posible, simplemente porque nada puede suceder dos veces, vamos a tratar su objeción con menos cortesía [...] Preguntaríamos si el teorema de binomio, tal como él lo conoce, es el mismo teorema que Newton inventó, ¿̨o no? Si dice que sí, habrá admitido todo lo que queremos. Si dice que no, podemos condenarlo fácilmente por contradecirse, ya que está asumiendo que en nuestro discurso mutuo tenemos ideas en común, y esto es inconsistente con su tesis (Collingwood, 1993: 446).

Uno puede alegar que el pensamiento del agente histórico y su reconstitución en la mente del historiador son dos copias exactas que simplemente son numéricamente distintas. Esto, Collingwood lo rechaza, aunque solo fuera porque nos implicaría en las dificultades "de la teoría de copia", que es la teoría "que pretende explicar cómo conocemos cosas sobre la hipótesis de imágenes 'dentro' de nuestras mentes, imágenes mentales, copiando las apariciones de objetos 'fuera' de nuestra mente" (Collingwood, I993: 449-450). Collingwood considera que esto ha sido definitivamente desacreditado por Appearance and Reality de F. H. Bradley (I897) ${ }^{28}$. Entre los muchos argumentos que Collingwood (I993) ofrece está la idea que al pensar los pensamientos del agente histórico y los del historiador, de alguna manera están confinados en sus cráneos, de modo que deben ser por lo menos numéricamente distintos ya que se encuentran en diferentes puntos del espacio y el tiempo, lo cual nos conduciría en última instancia - como el idealismo subjetivo en la teoría del conocimiento- al escepticismo respecto a las otras mentes y al solipsismo. ${ }^{29}$ No podemos exponer aquí un análisis detallado de éste y otros argumentos de Collingwood. ${ }^{\circ}$ Cabe señalar, sin embargo, que

26 Véase G. Frege (1984), 362, y E. Husserl (1970), 329-330. Futuros paralelos con Frege han sido acertadamente dibujados por Jan van der Dussen (1995).

27 Una diferencia interesante válida para una discussion más adelante, entre Frege y Husserl por un lado y Collingwood por otro lado es que Collingwood habla de "actos de pensamiento" cuando ellos hablarían más bien de comprender un "objeto de pensamiento", por ejemplo en este pasaje: "If [Euclid] thought 'the angles are equal' and I now think 'the angles are equal', granted that the time interval is no cause for denying that the two acts are one and the same, is the difference between Euclid and myself ground for denying it? There is no tenable theory of personal identity that would justify such a doctrine. Euclid and I are not (as it were) two different typewriters which, just because they are not the same typewriter, can never perform the same act but only acts of the same kind. A mind is not a machine with various functions, but a complex of activities; and to argue that an act of Euclid's cannot be the same as an act of my own because it forms part of a different complex of activities is merely to beg the question. Granted that the same act can happen twice in different context within the complex of my own activities, why should it not happen twice in two different complexes?" (Collingwood, 1993: 287-288).

28 Sobre estos temas, veáse Marion (2009).

29 Norman Malcolm (1977) formuló un argumento similar en Thought and Knowledge.

30 Para más estudios sobre Collingwood sobre la "identidad del pensamiento", ver: H. Saari (1984), H. Saari, 
Collingwood es consciente de que se enfrenta aquí, una vez más, al problema de la transposición:

¿Si ahora vuelvo a pensar un pensamiento de Platón, mi acto de pensamiento es idéntico al de Platón o es diferente? A no ser que sea idéntico, mi conocimiento presunto de la filosofía de Platón es un enorme error. Pero a menos que sea diferente, mi conocimiento de la filosofía de Platón implica el olvido de la mía. Lo que se requiere, si tengo que conocer la filosofía de Platón, es, a la vez, repensarla en mi propia mente y pensar otras cosas a la luz de las cuales podré juzgarla (Collingwood, I993: 300-301).

Si olvidamos la manera engañosa de expresarse de Collingwood, "re-pensar en mi propia mente", podemos ver en este pasaje que la solución de Collingwood implica que siempre debe haber una "reconstitución" idéntica, y que ésta siempre debe ser, al mismo tiempo, "pensamiento crítico".

En cuanto a este trabajo se refiere, Ricoeur dió en el punto decisivo:

Esta solución elegante [la idea que el agente histórico y los pensamientos del historiador son dos copias que son, simplemente, numéricamente distintas, CK у $\mathrm{MM}$ ] se equivoca al sumergir de nuevo los actos de pensar en el flujo del tiempo, mientras que por la reconstitución éstos están liberados de las limitaciones del tiempo (Ricoeur 1984, I3).

Esta es la razón por la que el pensamiento original y su reconstitución pueden ser vistos legítimamente como la misma cosa. Esto también encaja muy bien con el hecho de que estamos hablando de explicaciones racionales como opuestas a las causales. Por esta razón, es legítimo decir que se puede recuperar la intención del autor, independientemente de la "distancia temporal", lo que no equivale, por supuesto, a decir con un grado suficiente de certeza, que hay razones prácticas por lo cual esto puede ser, a menudo, imposible. Pensar el agente histórico y los pensamientos del historiador como numéricamente distintos es, pues, un error filosófico que abre la puerta al escepticismo, justamente el escepticismo sobre las intenciones del autor que uno encuentra en la hermenéutica de Gadamer, como resultado de su adopción de la "distancia temporal" en lugar de su rechazo.

Por supuesto, el historiador solo tiene una base para sus trazas de "reconstitución" de estos eventos en su propio presente, que ella debe interpretar y utilizar con el fin de inferir lo que pasó, es decir, proporcionar la "razón por la cual" o $\delta ı \tau \tau$, para usar la expresión de Aristóteles en Posterior Analytics, Libro I, sección I3. Podemos acceder a pensamientos del pasado no sólo porque dieron lugar a acciones que dejaron huellas físicas que nos son disponibles en el presente, sino 
también, diría Collingwood, porque están de alguna manera "encapsulados" en el presente. Para ver lo que él entiende por esto, tenemos que recordar que, aunque habló de la historia, como hemos visto, en términos de "acciones" y "eventos", Collingwood también se refirió a ella en términos de "procesos". De acuerdo con él

si un proceso Pi se convierte en un proceso $\mathrm{P}_{2}$, no hay ninguna línea divisoria en la cual Pi termina y P2 comienza [...] Si Pi ha dejado trazas de sí en $\mathrm{P}_{2}$ de modo que un historiador viviendo en $\mathrm{P}_{2}$ pueda descubrir por la interpretación de pruebas que lo que es ahora $\mathrm{P}_{2}$ alguna vez fue Pi, se deduce que 'las trazas' de Pi en el presente no son, por así decirlo, el cadáver de un Pi muerto, sino más bien el verdadero PI, el mismo Pi viviente y activo aunque encapsulado dentro de la otra forma de sí mismo, P2 (Collingwood, I993: 98).

Esta noción de "encapsulación", interesante tal cual, en realidad nunca ha sido estudiada en la literatura secundaria. Aunque en última instancia difiere, se parece a la noción de "supervivencia" que Collingwood conocía muy bien por su trabajo en antropología. ${ }^{31}$ A partir de este pasaje y del ejemplo que da en Autobiography sobre cómo llegar al pensamiento de Nelson "Con honor les gané, con honor moriré con ellos" (Collingwood, I939: II3-II4), se infiere que el punto clave de un "pensamiento encapsulado" es que sólo como resultado de una serie de preguntas y respuestas a partir de huellas disponibles en el presente y que conducen a una reconstrucción del contexto en el que la frase correspondiente fue pronunciada (un poco como un movimiento en una partida de ajedrez) podemos llegar a reconstituirla. Esto plantea toda una serie de preguntas, algunas posiblemente vinculadas al hecho de que Collingwood ha expresado, una vez más, sus pensamientos de maneras engañosas, pero este no es el lugar para un examen completo de esta noción intrigante. ${ }^{32}$

3I En efecto, Collingwood tiene en The New Leviathan una "Law of primitive survivals": "When A is modified into $B$ there survives in any example of $B$, side by side with the function $B$ which is the modified form of A, an element of A in its primitive or unmodified state" (Collingwood, I992: 9.5I). Se está refiriendo a la noción de 'survival' introducida por E. B. Tylor en Primitive Culture: "Among evidence aiding us to trace the course which the civilization of the world has actually followed, is that great class of fact to denote which I have found it convenient to introduce the term 'survivals'. These are processes, customs, opinions, and so forth, which have carried on by force of habit into a new state of society different from that which they had in their original home, and they thus remain as proofs and examples of an older condition of culture out of which a newer has been evolved" (Tylor, I913: I6). Collingwood conoció bastante bien el trabajo de Tylor, que discutió de manera crítica en $R$. G. Collingwood, The Philosophy of Enchantment, (2005).

32 Como Jan van der Dussen anotó, es al menos importante anotar que Collingwood usa de 'incapsulation' en dos contextos diferentes, i.e. cuando discute del proceso histórico o cuando habla de historia a parte objecti (como en la nota 79 arriba) y en el contexto bastante diferente de re-enactment o de la historia a parte subjecti. Para más sobre ello, ver van der Dussen (1995). 


\section{Concepciones subyacentes del Tiempo}

La posición de Collingwood no se reduce a su solución del problema de la transposición. Cuando se lo lee correctamente, comentarios como los citados en los apartados anteriores deben proporcionar razones por las que Collingwood debe seguir siendo de interés en el contexto post-historicista de Gadamer, y por lo tanto, después de Heidegger. Esto, Gadamer no lo vio, pero Ricoeur sí. Nos referimos aquí a la Parte II, capítulo 2 de Memory, History, Forgetting de Ricoeur (2004), que contiene un compromiso crítico sostenido con la concepción heideggeriana del tiempo, tal como se establece en el Capítulo vi de la División II de Being and Time (Heidegger, 1996). En su capítulo, Ricoeur desarrolla numerosos argumentos para mostrar la importancia del trabajo de los historiadores contra los prejuicios más bien ingenuos de Heidegger mostrados contra aquella misma disciplina. Una parte del problema, como bien lo vio Ricoeur, tiene que ver con la distinción de Heidegger entre el tiempo "auténtico", también llamado "la temporalidad primordial" o simplemente "la temporalidad", y el tiempo "no auténtico" o "dentro de la intratemporalidad" ("within-time-ness"), que también se etiqueta "tiempo vulgar" ${ }^{3}$. Se lo describe como una concepción del tiempo como hecho de una sucesión de momentos presentes discretos o "ahoras", como Heidegger los llama, en los cuales el futuro fluye a través del presente hacia el pasado, de modo que el "ahora" corriente se convierte en "transcurrido". Hay que señalar aquí las similitudes con nuestro modelo intuitivo del tiempo. Como es sabido, Heidegger opuso a este tiempo "inauténtico" un tiempo "auténtico", más primario para el cual el pasado no es simplemente un "ya no" (Vergangenheit), es un "habiendo sido" (Gewesenheit). Heidegger trató de "derivar" el primero del segundo (que lo haya logrado, es otro asunto). La razón de esto tiene que ver con la afirmación de que el Dasein no es temporal porque esté "en la historia" sino porque existe y puede existir históricamente sólo porque es temporal en el suelo de su ser (Heidegger, 1996).

Vimos en la sección 3 que la solución de Gadamer al problema de la transposición se basa en esta concepción del tiempo, es decir, en la "temporalidad" del Dasein. Heidegger pensó que había mostrado así, al mismo tiempo, que: "La interpretación vulgar del carácter temporal de la historia está justificada así dentro de sus límites" (Heidegger, 1996: 345).

Heidegger habla, con hybris filosófica, como si estuviese en condiciones de poner límites a la historia como disciplina, porque ésta, al parecer, se limita a la esfera del pasado "inauténtico", pasado secundario que es un mero "ya no" o "transcurrido". Ricoeur rechazó claramente esta posición, argumentando a tra-

33 Para una breve introducción a Heidegger sobre el tiempo veáse Dastur (I990). 
vés de su capítulo, en favor de "un diálogo crítico entre la filosofía y la historia" (Ricoeur, 2004: 376). Entre sus argumentos hay uno que muestra perspicacia, ya que señala que Heidegger nunca se enfrenta realmente a la "profesión de historiador"; en vez de eso, ataca el tipo "científico y teórico del tratamiento del problema de la "historia"' (Heidegger, 1996: 344), que encuentra en los filósofos neo-kantianos de su época, como Windelband o Rickert (Ricoeur, 2004: 376). Es en este contexto que las ideas de Collingwood se vuelven interesantes.

Como hemos visto, Collingwood distingue entre el "adentro" y el "exterior" de un evento pasado, y argumenta que el historiador busca una explicación del evento en términos del exterior en términos del interior, es decir, conforme a una descripción "intencional". Esto lo condujo a la idea que, aunque los eventos ocurren dentro del flujo del tiempo "físico", esto es irrelevante para la admisión de explicaciones "intencionales". Así fue conducido a la idea que el tipo peculiar de la explicación que requería aquí, la "reconstitución", se haría a partir de los mismos pensamientos de los agentes históricos, ya que no habría ningún foso temporal (o espacial) para colmar, fuera del flujo del tiempo "físico". Ahora bien, los escritos de Collingwood contienen largas y bien conocidas críticas a los historiadores que practicaron lo que él llamaba una forma de "recorte-y-pegue" de la historiografía, ${ }^{34}$ lo cual es una crítica a los historiadores que se limitan a la noción de tiempo "físico", y simplemente compilan testimonios de eventos pasados, sin tratar de transformar esta compilación en una narrativa que dé explicaciones racionales o intencionales. Argumenta en detalle, en sus obras posteriores, en contra de la opinión de que la historia tiene que ver con lo que él llamó "el pasado muerto" de procesos naturales como el de la evolución en biología, a diferencia del "pasado viviente" que está "encapsulado" en el presente (Collingwood, 1939: 106). Fustiga a Spengler, por ejemplo, por su uso de la noción equivocada de tiempo en su estudio de las culturas en términos de procesos naturales, para terminar hablando del "ciclo vital" de las culturas, como si fueran organismos, etc. (Collingwood, I939: 106). Así podemos ver cuán sutil es la actitud de Collingwood hacia el tiempo. Para usar ahora la jerga de Heidegger, éste de hecho introduce junto con el "tiempo vulgar" de los historiadores de "recorte-y-pegue", otra noción de tiempo, que considera como presupuesto por cualquier intento de explicación racional o intencional del "interior" de los eventos pasados. $\mathrm{O}$, más bien Collingwood argumenta que esos pensamientos implicados en tales explicaciones quedan fuera del "tiempo vulgar".

Ricoeur ya estaba de acuerdo con Collingwood sobre este punto en el volumen 3 de Time and Narrative: "[me suscribo] sin reservas a la tesis de Collingwood

34 Para una crítica detallada, véase (Collingwood, 1993). 
que traza una línea divisoria entre las nociones de cambio y evolución por un lado, y de historia por el otro" (Ricoeur 1988, 9I).35

Habría que señalar cómo, la sagaz lectura que hace Ricoeur de Collingwood, evidencia claramente que la crítica de Collingwood de la historia tipo "recortey-pegue" está ligada a la afirmación de que ella presupone la concepción incorrecta, la de tiempo "físico". Collingwood piensa en efecto que la producción del historiador de "recorte-y-pegue" se estropea por el hecho que trabaja con la concepción errónea de tiempo, es decir, con la misma concepción encarnada en el modelo intuitivo de tiempo que presentamos al principio de este trabajo. En otras palabras, una buena historiografía se mueve en otro plano temporal que el de la física y esto significa que las explicaciones históricas tienen otra forma. Ricoeur expresa el mismo punto en Memory, History, Forgetting:

Medio siglo más tarde, Collingwood se hace eco de Michelet con un tema más sombrío, él de la "reconstitución" [sic] del pasado en el presente. Siguiendo este concepto, la operación historiográfica aparece como un in-distanciamiento —una identificación con lo que una vez fue. Pero esto es a costa de extraer del evento físico su cara 'interna', lo cual puede llamarse pensamiento. Al final de una reconstrucción que moviliza la imaginación histórica, el pensamiento del historiador puede ser considerado una manera de repensar lo que una vez fue pensado. En cierto sentido, Collingwood anuncia a Heidegger: 'El pasado, en un proceso natural, es un pasado reemplazado y muerto' (The Idea of History, 225). Ahora, en la naturaleza, los instantes mueren y son reemplazados por otros. Sin embargo, el mismo evento, conocido históricamente, "sobrevive en el presente" (225). Su supervivencia reside en el acto mismo de su reconstitución en el pensamiento. Esta concepción basada en la identidad omite el momento de alteridad incluido en la idea de 'repetición'; [...] (Ricoeur 2004: 380-38I).

Estas observaciones requieren dos comentarios. El primero tiene que ver con la crítica de Ricoeur: "Esta concepción basada en la identidad omite el momento de alteridad incluido en la idea de 'repetición", que es evocadora del comentario de Gadamer, citado arriba, que "la dimensión de mediación hermenéutica que se transmite en cada acto de comprensión todavía se escapa [Collingwood]". La evidente dificultad con comentarios como estos es que se limitan a declarar que Collingwood sostiene una opinión que ellos, Gadamer y Ricoeur, rechazan; una mera declaración de diferencias de opinión no es un argumento en sí mismo. Encontramos uno de estos argumentos en la conferencia de Ricoeur en The Reality of the Historical Past, incluida de nuevo en el volumen 3 de Time and

35 La traducción inglesa tiene, erróneamente, "ascribe”, y desde luego se lee "I unreservedly ascribe to Collingwood" por "je me rallie sans réserve à la thèse de Collingwood". 
Narrative, donde la sección sobre Collingwood fue sustancialmente modificada (Ricoeur, 1988), en la cual Ricoeur utiliza, de repente, la teoría de Platón de los 'tipos principales' en Sophist 2254b-259d, seleccionando lo Mismo, lo Otro y lo Análogo, relacionándolos con las filosofías de la historia de Collingwood, Michel de Certeau y Hayden White, respectivamente. Este paso le permite criticar a Collingwood por haber promovido una visión de la historia "a base de identidad" a diferencia de una visión "dialéctica", que mantiene el "Yo" y el "Tú" claramente separados y autónomos. Ricoeur apunta aquía la afirmación de Collingwood que una reconstitución lograda se traduce en que el historiador elabore pensamientos idénticos a los del agente histórico, y no meras copias: "Para que [el "cuadro imaginario del pasado"] sea lo mismo, tiene que ser numéricamente idéntico al pasado. Repensar tiene que ser una manera de anular la distancia temporal. Esta aniquilación constituye el significado filosófico (híper-epistemológico) de la reconstitución" (Ricoeur, I988: I46).

Ricoeur está tergiversando a Collingwood en esta cita: la identidad que Collingwood afirma no es, como hemos visto, la identidad numérica y, además, si estamos en lo cierto, nunca tuvo la intención de anular la distancia temporal, sino más bien la de negar que haya alguna, que no es lo mismo. En todo caso, se podrían plantear cuestiones relativas a la adecuación del empleo de Ricoeur, fuera de contexto, "tipos principales" de Platón — la naturaleza ad hoc de la estructura del argumento es sorprendente- pero no haremos hincapié en este punto y simplemente notaremos que es una lástima que a Ricoeur, sensible como lo era sobre esta cuestión, se le haya escapado el hecho de que la "lógica de preguntas y respuestas" de Collingwood, es decir el proceso que conduce a la "reconstitución", es de gran interés precisamente porque es "dialógico", en contraposición a "monológico". ${ }^{66}$ En otras palabras, a pesar de que Collingwood no haya hecho una tormenta con ésto, la inferencia histórica tal como la concibió, no es un proceso interno, sino que es un proceso de interacción entre el "Yo" y el "Tú", para usar una jerga que le es ajena. Que las inferencias históricas puedan conducir a conclusiones verdaderas sobre lo que está ahí afuera, por así decirlo, o la reconstitución de pensamientos en ese sentido peculiar de que el pensamiento original y el reconstituido son lo mismo, no anula su carácter interactivo.

El segundo punto tiene que ver con el rapprochement que hace Ricoeur entre Collingwood y Heidegger. Hay límites obvios al mismo que son, precisamente,

36 Sobre la distinción entre lo "dialógico" y el de ahora en adelante estándar "monológico" vision de la inferencia, que recuerda Platón y Aristóteles, véase Marion, "Game Semantics and The Manifestation Thesis," en M. Marion, G. Primiero \& S. Rahman (eds.), The Anti-Realism Debate in the Age of Alternative Logics (Dordrecht, Springer) AÑo. On the non-eliminable role of the 'Thou' in a dialectical game, see also Castelnérac \& Marion, 'Arguing for Inconsistency'. 
el tema de este trabajo. Seguramente no hay ninguna idea en Collingwood que corresponda realmente a la idea existencial de Heidegger de "temporalidad primordial", pero, considerando la manera como Ricoeur hizo uso de la noción de Heidegger para intentar dar cuenta de la variedad de fenómenos en historiografía que pasan bajo el nombre de "mémoire", nos gustaría sugerir la noción de Collingwood de "encapsulación" como una contraparte posible. En su Autobiography, trató de transmitir la idea con la ayuda del ejemplo de un fumador que dejó de fumar, pero mantiene el deseo de fumar:

Encapsulación no es una "entidad oculta". Era mi nombre para un hecho como éste - suficientemente familiar para todo el mundoen el que un hombre que cambia sus hábitos, pensamientos, etc., retiene en la segunda fase un residuo de lo primera. Él deja de fumar, pero su deseo de fumar con eso no desaparece. En su vida subsecuente el deseo es lo que llamo encapsulado. Sobrevive, y produce resultados, pero estos resultados no son lo que eran, antes de que dejara de fumar. No consisten en fumar. El deseo sobrevive en forma de un deseo insatisfecho. Si se lo encuentra fumando otra vez, eso no necesariamente demuestra que nunca dejó de fumar; bien puede ser porque nunca perdió el deseo, y cuando los motivos contra la satisfacción del deseo desaparecieron, empezó una vez más a satisfacerlo (Collingwood, 1939: I4O-I4I).

Lo que dice Collingwood no es, como afirma Ricoeur, que algo sobrevive en el presente porque es reconstituido, sino que es porque sobrevive "encapsulado" en el presente que un pensamiento es reconstituible. El ejemplo puede que no sea óptimo, pero "encapsulación" podría ofrecer justamente los recursos conceptuales necesarios para dar cuenta de "la mémoire", ya que esto es precisamente la materia que está "encapsulada" en el presente, y que requiere un proceso "de preguntas y respuestas" para su "reconstitución", lo cual, a su vez, no presupone nuestro modelo intuitivo del tiempo.

\section{Conclusión}

A diferencia de Gadamer, cuya comprensión de la distancia temporal está profundamente inmersa en las tradiciones de la hermenéutica teológica y jurídica, es decir, hermenéutica "textual", Collingwood fue un médico y un verdadero arqueólogo e historiador, y era claro para él que los principios de su teoría de la interpretación se derivan de su actividad como arqueólogo (Collingwood, I939: I40-I4I). Mientras que el background de Gadamer lo condujo a una visión más relativista de la comprensión como algo que nunca pretende recuperar la intención del autor, los argumentos de Collingwood van simplemente en el sentido 
de que no hay ninguna razón en principio para reconocer que una 'reconstitución' acertada permita recuperar la intención del autor; no quería dejar lugar a esa clase de escepticismo que alimenta una forma de "relativismo" que él, qua arqueólogo o historiador, habría encontrado inaceptable. ${ }^{37}$

Collingwood fue llevado para acentuar un modelo tipo "detective" de investigación en el cual se puede llegar a conocer hechos del pasado, incluyendo la intención de un autor. ${ }^{38}$ Que este modelo no sea popular después del pretendido "linguistic turn", es otro tema. En este trabajo, se trataba simplemente de dar una de las razones por las cuales las ideas de Collingwood, bien entendidas, deben seguir siendo de interés. Comenzamos con un modelo intuitivo de tiempo, explicando cómo esto presta apoyo al escepticismo mismo, subyacente a visiones relativistas sobre el significado, y luego mostramos que Gadamer adoptó la noción de "distancia temporal" incorporada en este modelo, en su propia solución al problema de la transposición que asoló la hermenéutica de Dilthey. Entonces mostramos cómo Collingwood, lejos de ser debilitado con aquel problema, como podría pensar quien sólo ha leído la exposición de Gadamer de sus concepciones, era realmente consciente de ello y propuso una solución radical según la cual simplementes no hay ninguna "distancia temporal", que no hay ningún foso para colmar, y esa es precisamente la razón por la cual se puede tener la sensación de que podemos conocer, en un sentido fuerte de la palabra, no sólo los hechos del pasado sino, también, las intenciones de los agentes históricos o autores del pasado.

No pretendimos solucionar aquí ninguno de los grandes temas que planteamos al comienzo del trabajo. Nuestro objetivo era modesto. La teoría de la interpretación de Collingwood no está ciertamente de acuerdo con los prejuicios filosóficos de nuestros tiempos, aunque posiblemente esté de acuerdo con la mayoría silenciosa de los historiadores. Esperamos haber demostrado que es filosóficamente más interesante, ya que acaba con una visión ingenua de la "distancia temporal" que permanece en la obra de Gadamer.

37 Es interesante notar cómo Gadamer se vuelve notariamente enfadado cuando se discute un crítica muy famosa del relativismo según la cual esta doctrina se auto-contradice: describe este argumento como "sofismo" (Gadamer, 1989). Sólo tiende a mostrar que, en la terminología de Collingwood, nos acercamos a sus "presuposiciones absolutas" (Collingwood, 1999). Por otro lado, Collingwood creía que ciertas inferencias en la historia están tan bien sustentadas que simplemente no las podemos deshacer (Collingwood, 1993). ¿Esto puede ser controvertido, pero que quisiera correr desde un argumento escéptico a una conclusión de la cual uno no pudiera nunca estar absolutamente seguro de su propio cumpleaños? ¿Quién es el que no pudiera estar seguro de su propio cumpleańos? ¿Qué pudiera significar "certeza" en estos contextos?

38 Jan van der Dussen dibujó paralelos entre este "detective model" y Peirce sobre el abductive reasoning en el ensayo dado en el colloquio internacional Collingwood et la philosophie du vingtième siècle/Collingwood and Twentieth-Century Philosophy, en Université du Québec à Montréal en Octubre 2007. 


\section{Referencias}

Anscombe, G. e. M., 1957, Intention, Oxford, Blackwell.

Austin, J., L., 1962, Sense and Sensibilia, Oxford, Oxford University Press.

Ayer, A. J., 1940, The Foundations of Empirical Knowledge, London, MacMillan.

Bambach, C. R., 1995, Heidegger, Dilthey, and the Crisis of Historicism, Ithaca NY, Cornell University Press.

Bradley, F. H., I897, Appearance and Reality, sec. ed., Oxford, Oxford Univerisity Press.

Castelnérac, B. \& M. Marion, 2009, 'Arguing for Inconsistency: Dialectical Games in the Academy', in G. Primiero \& S. Rahman (eds.), Acts of Knowledge: History, Philosophy and Logic, London, College Publication, 37-76.

Collingwood, R. G., 1924, Speculum Mentis or The Map of Knowledge, Oxford, Clarendon Press.

Collingwood, R. G., 1932, Roman Britain, Oxford, Clarendon Press.

Collingwood, R. G. \& J. N. L. Myres, 1936, Roman Britain and the English Settlements, Oxford, Clarendon Press.

Collingwood, R. G., 1938, Principles of Art, Oxford, Clarendon Press.

Collingwood, R. G., 1939, An Autobiography, Oxford, Clarendon Press.

Collingwood, R. G., I955, Denken. Eine Autobiographie, Stuttgart, K. F. Koehler Verlag.

Collingwood, R. G., 1992, The New Leviathan or Man, Society, Civilization \& Barbarism, revised edition, Oxford, Clarendon Press. (Ist edition 1942.)

Collingwood, R. G., 1994, The Idea of History, revised edition, Oxford, Clarendon Press. (Ist edition 1946.)

Collingwood, R. G., 1998, An Essay on Metaphysics, Oxford, Clarendon Press (Ist edition 1940.)

Collingwood, R. G., 2005, The Philosophy of Enchantment. Studies in Folktale, Cultural Criticism, and Anthropology, Oxford, Clarendon Press.

Connelly, J. \& A. Costall, 2000, 'R. G. Collingwood and the Idea of a Historical Psychology', Theory and Psychology, vol. I0, I47-170.

Danto, A., 2007, Narration and Knowledge, New York NY, Columbia University Press. 
Dastur, F., 1990, Heidegger and the Question of Time, Atlantic Highlands NJ, Humanities Press.

Davidson, D., 200I, Essays on Actions and Events, Oxford, Clarendon Press.

Derrida, J., 1979, Spurs. Nietzsche's Styles, Chicago, University of Chicago Press.

Dilthey, W., 1924, Die Gestige Welt: Einleitung in die Philosophie des Lebens. Gesammelte Schriften, vol. 5, Leipzig \& Berlin, B. G. Teubner.

Dilthey, W., 1927, Der Aufbau der geschichtlichen Welt in den Geisteswissenschaften Gesammelte Schriften, vol. 7, Leipzig \& Berlin, B. G. Teubner.

D'Oro, G., 2000, 'Collingwood on Re-Enactment and the Identity of Thought', Journal of the History of Philosophy, vol. 38, 87-IOI.

D’Oro, G., 2007, 'Two Dogmas of Contemporary Philosophy of Action', Journal of the Philosophy of History, vol. I, IO-24.

Dummett, M. A. E., 1993, Origins of Analytical Philosophy, London, Duckworth.

Frege, G., 1984, Collected Papers on Mathematics, Logic and Philosophy, Oxford, Blackwell.

Gabriel, G., 1986, 'Frege als Neukantianer', Kantstudien, vol. 77, 84-IOI.

Gadamer, H.-G., 1955, 'Einleitung', in Collingwood (1955), v-XIv. English translation: Introduction to Denken, the German Translation of An Autobiography', The Collingwood

Journal, spring 1992, 9-I4.

Gadamer, H.-G., 1976, Philosophical Hermeneutics, Berkeley CA, University of CaliforniaPress.

Gadamer, H.-G., 1987, 'The Problem of Historical Consciousness', in P. Rabinow \& W. M.Sullivan (eds.), Interpretive Social Science. A Second Look, Berkeley, Univerisity of California Press, 82-I40.

Gadamer, H.-G., 1989, Truth and Method, second edition, New York, Continuum. Gadamer, H.-G., I99I, Plato's Dialectical Ethics. Phenomenological Interpretations Relating to the Philebus, second edition, New Haven, Yale University Press.

Gardiner, P., 1952, 'The Object of Historical Knowledge', Philosophy, vol. 27, 2II-22O.

Habermas, J., 1978, Knowledge and Human Interests, second edition, New York NY, Beacon Press. 
Heidegger, M., 1996, Being and Time, Albany NY, State University New York Press. Husserl, E., 1970, Logical Investigations, vol. I, London, Routledge.Lotze’s Logic (Oxford, Clarendon Press, I884)

Malcolm, N., 1977, Thought and Knowledge, Ithaca, Cornell University Press.

Marion, M., 2000, 'Oxford Realism: Knowledge and Perception', British Journal for the History of Philosophy, vol. 8, 299-338 \& 485-519.

Marion, M., 2009a, 'John Cook Wilson', The Stanford Encyclopedia of Philosophy (Winter 2009 Edition), E. N. Zalta (ed.), URL = http://plato.stanford.edu/ entries/wilson/

Marion, M., 2009b, 'Theory of Knowledge in Britain I850-1950: A NonRevolutionary

Account', The Baltic International Yearbook of Cognition, Logic and Communication, vol. 4,URL = http://thebalticyearbook.org/journals/baltic/article/view/129/67 Marion, M., 20II, 'Game Semantics and The Manifestation Thesis', in M. Marion, G. Primiero \& S. Rahman (eds.), The Anti-Realism Debate in the Age of Alternative Logics, Dordrecht, Springer, under press.

Michelfelder, D. P. \& R. e. Palmer (eds.), 1989, Dialogue \& Deconstruction. The Gadamer-Derrida Encounter, Albany NY, sunY Press.

Mink, L. O., I969, Mind, History, and Dialectic: The Philosophy of R. G. Collingwood,Bloomington, Indiana University Press.

Oakeshott, M. J., 1933, Experience and its Modes, Cambridge, Cambridge University Press.

Ricoeur, P., 1984, The Reality of the Historical Past, Milwaukee, Marquette University Press.

Ricoeur, P., 1988, Time and Narrative. Volume 3, Chicago IL, University of Chicago Press.

Ricoeur, P., 2004, Memory, History, Forgetting, Chicago IL, University of Chicago Press.

Rorty, R. (ed.), 1967, The Linguistic Turn. Recent Essays in Philosophical Method, Chicago IL, University of Chicago Press.

Saari, H., 1984, Re-enactment: a Study in R. G. Collingwood's Philosophy of History, Åbo, Åbo Akademi. 
Saari, H., 1989, 'R. G. Collingwood on the Identity of Thoughts', Dialogue, vol. 28, 77-89.

Skinner, Q., 200I, 'The Rise of, Challenge to and Prospects for a Collingwoodian Approach to the History of Political Thought' in D. Castiglione \& I. HampsherMonk (eds.), The History of Political Thoguht in National Context, Cambridge, Cambridge University Press, 175-188.

Stueber, K. R., 2002, 'The Psychological Basis of Historical Explanation: Reenactment,Simulation, and the Fusion of Horizons ', History and Theory, vol. 4I, 25-42.

Tylor, E. B., 1913, Primitive Culture. Researches into the Development of Mythology, Philosophy, Religion, Language, Art, and Custom, 4th edition, 2 vols., London, John Murray. 